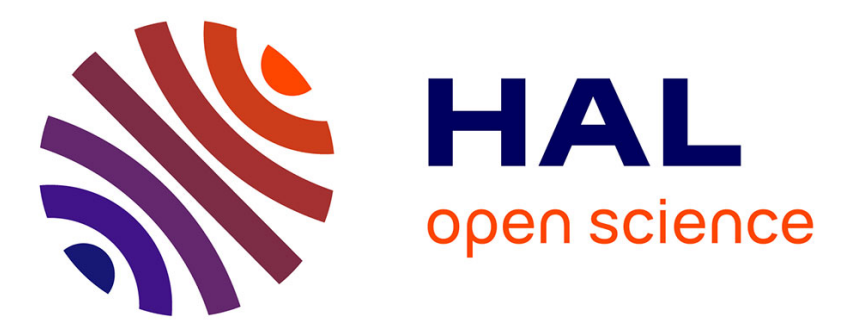

\title{
Description of the flow in a linear cascade with an upstream cavity part 2: Assessing the loss generated using an exergy formulation (draft)
}

Maxime Fiore, Nicolas Gourdain, Jean-François Boussuge, Eric Lippinois

\section{- To cite this version:}

Maxime Fiore, Nicolas Gourdain, Jean-François Boussuge, Eric Lippinois. Description of the flow in a linear cascade with an upstream cavity part 2: Assessing the loss generated using an exergy formulation (draft). Computers and Fluids, 2020, 199, pp.104360-104370. 10.1016/j.compfluid.2019.104360 . hal02880035

\section{HAL Id: hal-02880035 \\ https://hal.science/hal-02880035}

Submitted on 24 Jun 2020

HAL is a multi-disciplinary open access archive for the deposit and dissemination of scientific research documents, whether they are published or not. The documents may come from teaching and research institutions in France or abroad, or from public or private research centers.
L'archive ouverte pluridisciplinaire HAL, est destinée au dépôt et à la diffusion de documents scientifiques de niveau recherche, publiés ou non, émanant des établissements d'enseignement et de recherche français ou étrangers, des laboratoires publics ou privés. 


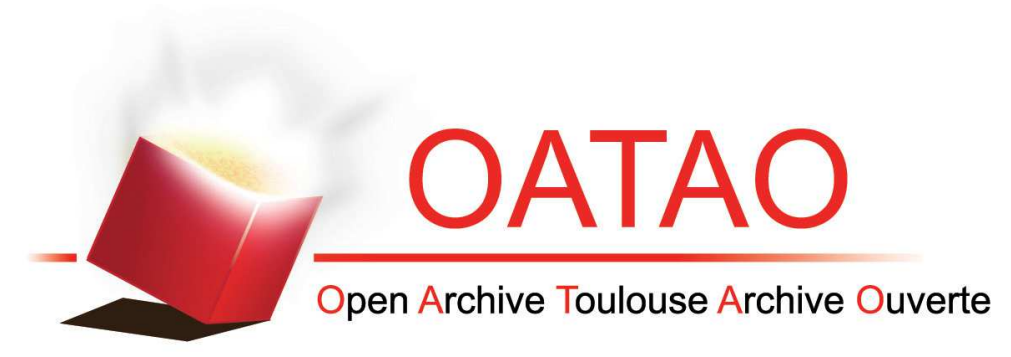

\section{Open Archive Toulouse Archive Ouverte (OATAO)}

OATAO is an open access repository that collects the work of some Toulouse researchers and makes it freely available over the web where possible.

This is an author's version published in: https://oatao.univ-toulouse.fr/25971

Official URL: https://doi.org/10.1016/j.compfluid.2019.104360

\section{To cite this version :}

Fiore, Maxime and Gourdain, Nicolas and Boussuge, Jean-François and Lippinois, Eric Description of the flow in a linear cascade with an upstream cavity part 2: Assessing the loss generated using an exergy formulation (draft). (2020) Computers and Fluids, 199. 104360-104370. ISSN 0045-7930

Any correspondence concerning this service should be sent to the repository administrator: tech-oatao@listes-diff.inp-toulouse.fr 


\title{
Description of the flow in a linear cascade with an upstream cavity part 2: Assessing the loss generated using an exergy formulation (draft)
}

\author{
M. Fiore ${ }^{\mathrm{a}, 1, *}$, N. Gourdain ${ }^{\mathrm{b}}$, J.-F. Boussuge ${ }^{\mathrm{a}}$, E. lippinois $^{\mathrm{c}}$ \\ a CERFACS, Computational Fluid Dynamics team, Toulouse, France \\ ${ }^{\mathrm{b}}$ ISAE-Supaero, Dpt. of Aerodynamics, Energetics and Propulsion, Toulouse, France \\ ' Safran Aircraft Engines, Moissy-Cramayel, France
}

Keywords:

Large-Eddy simulation

Turbulence injection

Transition process

Aerodynamic losses

Exergy analysis

Low-pressure turbine

\begin{abstract}
A B S T R A C T
Purge air is injected in cavities at hub of axial turbines to prevent hot mainstream gas ingestion into interstage gaps. This process induces additional losses for the turbine due to an interaction between purge and mainstream flow. To deal with this issue, this paper is devoted to the study of a low speed linear cascade with an upstream cavity at a Reynolds number representative of a low-pressure turbine using RANS and LES with inlet turbulence injection. Different rim seal geometries and purge flow rates are studied. Details about numerical methods and comparison with experiments can be found in a companion paper. The analysis here focuses on the loss generation based on the description of the flow and influence of the turbulence introduced in the companion paper. The measure of loss is based on an exergy analysis (i.e. energy in the purpose to generate work) that extends a more common measure of loss in gas turbines, entropy. The loss analysis is led for a baseline case by splitting the simulation domain in the contributions related to the boundary layers over the wetted surfaces and the remaining domain (i.e. the complementary of boundary layers domains) where secondary flows and related loss are likely to occur. The analysis shows the strong contribution of the blade suction side boundary layer, secondary vortices in the passage and wake at the trailing edge on the loss generation. The study of different purge flow rates shows increased secondary vortices energy and subsequent loss for higher purge flow rates. The rim seal geometry with axial overlapping promotes a delayed development of secondary vortices in the passage compared to simple axial gap promoting lower levels of loss.
\end{abstract}

\section{Introduction}

Rotor-stator wheel space in low-pressure turbines implies gaps often referred to cavities under the main flow passage in which hot turbine gas could be ingested. This hot flow could impinge rotor disks leading to potential overheating and damages for the turbine [3]. Some relative cold air is blown from the compressor to feed and seal turbine cavities and prevent partially hot-gas ingestion from the main annulus [25]. Part of this air called purge flow blows into the mainstream through the rim seal. The literature gives some insight on the influence of cavity and purge flow on the loss in turbines with generally a detrimental effect [22]. The purge flow reinforces the horse shoe vortex process at the blade leading edge as stated by Kost and Nicklas [17] and more gener-

\footnotetext{
* Corresponding author.

E-mail addresses: fiore@cerfacs.fr, maxime.fiore@cerfacs.fr (M. Fiore).

1 orcid=0000-0003-1740-4581
}

ally of secondary flows in the passage. In a rotor-stator configuration with cavity in-between, Reid et al. [33] reported the influence of mixing process at the rim seal interface and perturbed rotor secondary flows by purge flow as mechanisms inducing additional losses in the turbine. However, the direct link between the purge flow and losses generated in the main annulus remains generally difficult to draw and quantify especially when using loss in total pressure. The entropy/exergy approach can provide additional insight in the mechanisms of loss. The notion of loss in gas turbines has been widely studied from a general and theoretical sight by Horlock [15] comparing a wide range of gas turbine architecture and introducing the notion of availability function or equivalently exergy. This quantity makes possible to account for both the energy contained in the flow with total enthalpy and the level of irreversibility in the flow with entropy that will reduce the energy available to generate work. This analysis is compliant with the use of entropy to account for the loss generated in a gas turbine that is currently widely used to assess the loss generation 


\begin{tabular}{|c|c|}
\hline \multicolumn{2}{|c|}{ Nomenclature } \\
\hline \multicolumn{2}{|c|}{ Latin letters } \\
\hline$(s, c, r)$ & local stream coordinates [m] \\
\hline$(x, y, z)$ & Cartesian coordinates [m] \\
\hline & mass flow rate $\left[\mathrm{kg} \cdot \mathrm{s}^{-1}\right]$ \\
\hline$\dot{Q}$ & internal heat source $\left[\mathrm{kg} \cdot \mathrm{m}^{2} \cdot \mathrm{s}^{-2}\right]$ \\
\hline$C_{x}$ & axial chord-length $[\mathrm{m}]$ \\
\hline$\hat{h}$ & enthalpy $\left[\mathrm{kg} \cdot \mathrm{m}^{2} \cdot \mathrm{s}^{-2}\right]$ \\
\hline$k$ & turbulent kinetic energy $\left[\mathrm{kg} \cdot \mathrm{m}^{2} \cdot \mathrm{s}^{-2}\right]$ \\
\hline$P_{k}$ & turbulent kinetic energy production $\left[\mathrm{kg} \cdot \mathrm{m}^{2} \cdot \mathrm{s}^{-3}\right]$ \\
\hline $\mathrm{Tu}$ & turbulence intensity $[-]$ \\
\hline$u$ & velocity $\left[\mathrm{m} . \mathrm{s}^{-1}\right]$ \\
\hline E & energy $\left[\mathrm{kg} \cdot \mathrm{m}^{2} \cdot \mathrm{s}^{-2}\right]$ \\
\hline $\mathrm{H}_{\mathrm{NGV}}$ & blade height $[\mathrm{m}]$ \\
\hline Ma & Mach number[-] \\
\hline $\mathrm{q}$ & heat transfer [kg.s ${ }^{-3}$ ] \\
\hline $\operatorname{Re}$ & Reynolds number $[-]$ \\
\hline s & entropy $\left[\mathrm{kg} \cdot \mathrm{m}^{2} \cdot \mathrm{s}^{-2} \cdot \mathrm{K}^{-1}\right]$ \\
\hline \multicolumn{2}{|c|}{ Greek letters } \\
\hline$\chi$ & exergy $\left[\mathrm{kg} \cdot \mathrm{m}^{2} \cdot \mathrm{s}^{-2}\right]$ \\
\hline$\delta$ & boundary layer thickness [m] \\
\hline$\gamma$ & sealing flow angle, $\tan ^{-1}\left(u_{z} / u_{x}\right)$ [deg] \\
\hline$\kappa$ & artificial viscosity coefficient $[-]$ \\
\hline$\lambda$ & thermal conductivity $\left[\mathrm{kg} \cdot \mathrm{m} \cdot \mathrm{s}^{-3} \cdot \mathrm{K}^{-1}\right]$ \\
\hline$\mu$ & dynamic viscosity $\left[\mathrm{kg} \cdot \mathrm{m}^{-1} \cdot \mathrm{s}^{-1}\right]$ \\
\hline$\Phi$ & anergy $\left[\mathrm{kg} \cdot \mathrm{m}^{2} \cdot \mathrm{s}^{-2}\right]$ \\
\hline$\tau$ & viscous stress tensor $\left[\mathrm{kg} \cdot \mathrm{m}^{-1} \cdot \mathrm{s}^{-2}\right]$ \\
\hline \multicolumn{2}{|c|}{ Subscripts and superscripts } \\
\hline$:$ & production term \\
\hline$\overline{-}$ & Reynolds/temporally averaged quantity \\
\hline 0 & reference state \\
\hline c & cavity \\
\hline eff & effective contribution \\
\hline in/out & inlet/outlet condition \\
\hline $\mathrm{m}$ & main annulus \\
\hline sgs & sub-grid scale contribution \\
\hline tot & total quantity/contribution \\
\hline turb & turbulent contribution \\
\hline visc & viscous contribution \\
\hline
\end{tabular}

in gas turbines [20,21,24] as popularized by Denton [7]. In addition, this approach makes possible to account for potential heat and work transfers between the flow and the gas turbine. The entropy/exergy approach made possible to give additional insight in the mechanisms of loss associated to purge flow as studied by Reid et al. [33] and Zlatinov et al. [42] showing that a reduction losses could be achieved by promoting a swirled purge flow before to interact with the main annulus flow. This approach can be coupled with the Computational Fluid Dynamics (CFD) tool to study the influence of purge flow on the loss generated in the turbine. The current design of turbines is mainly performed using Reynolds Averaged Navier Stokes (RANS) approach where all scales of turbulence are modelled. However, the interaction processes between cavity and main annulus flow are inherently unsteady [32]. The relatively low Reynolds number considered in lowpressure turbines $\left(\operatorname{Re} \sim 10^{5}\right.$ ) makes more and more feasible wallresolved Large Eddy Smulations (LES) [34] that resolve the turbulent unsteady flow field. Lower levels of turbulence modelling are obtained for LES approach compared to RANS $[38,39]$ that may expect a better resolution of the flow field at the interface between cavity and main annulus flow. From a loss perspective, recent studies have shown that the assessment of loss in a gas turbine can be

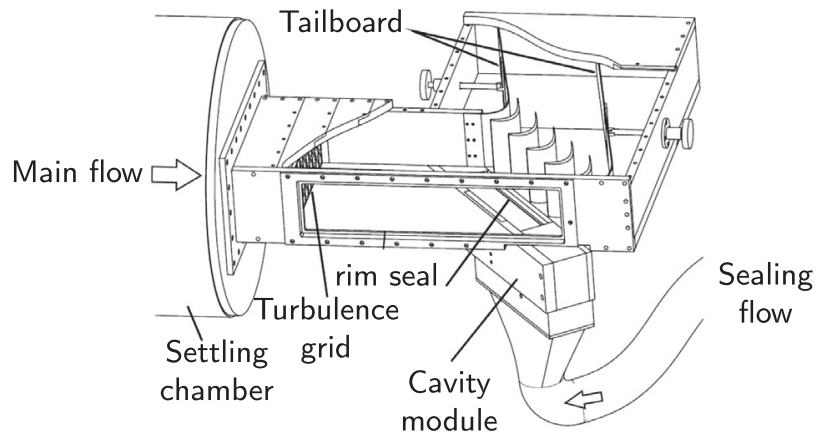

Fig. 1. View of the experimental set up. Adapted from Schuler [36].

obtained more accurately by LES compared to RANS $[18,20]$, this being due to a better resolution of turbulent field that drives the mixing process of momentum and enthalpy which in turns controls the level of losses generated in the flow field [35].

This paper uses the exergy formalism to draw the loss generated in a low-speed linear cascade with an upstream cavity including a parametric study of the purge flow rate supplied to the cavity and the rim seal geometry. The companion paper showed the good behavior of RANS approach to describe the flow field in the linear cascade with the finer agreement obtained for the LES with inlet turbulence injection ( LES $_{\text {turb.inj. }}$. . The two simulations are compared based on the exergy analysis to provide the differences between the two approaches from a loss perspective. The LES $_{\text {turb.inj. }}$ is then used to draw the exergy analysis for a baseline case. Following that, the influence of the purge flow rate and rim seal geometry on the loss generation is studied in this paper before to draw conclusions.

\section{Configuration and numerical methods}

A summary of the test case and numerical methods is provided below. More informations can be found in the companion paper. The test case considered for this study is a low-Mach linear cascade composed of five nozzle guide vane reprensentative of a modern low-pressure turbine design installed at Karlsruhe University, Germany (see Fig. 1). The mean Reynolds number based on axial chord and vane exit velocity is 500,000 typical of a mediumsized low-pressure turbine at take-off [16]. The free-stream turbulence is produced by a turbulence grid positioned at seven axial chord length upstream of the blade leading edge and was measured at midspan giving a turbulent intensity of $\mathrm{Tu}=6 \%$ at the blade leading edge. Upstream of the blade leading edge, the rim seal is included in a cavity module linked to the test section allowing to easily set different rim seal designs. The purge flow is supplied to the cavity as a fraction of the mainstream flow, respectively $\dot{m}_{\mathrm{c}} / \dot{m}_{\mathrm{m}}=0,0.5$ or $1 \%$. Main rig characteristics are gathered in Tab. 1. Three different rim seal geometries are studied during the experiments with a first geometry composed of an axial clearance (A) and two geometry using axial overlapping geometries: simple (S) and double (D) (see Fig. 2). The different cases studied with the different geometries and purge flow rates are de-

Table 1

Characteristics of the cascade rig.

\begin{tabular}{llll}
\hline cascade details & & \multicolumn{2}{l}{ nominal conditions } \\
\hline Inlet blade angle & $37.9^{\circ}$ & $\mathrm{Re}$ & $5.6 \times 10^{5}$ \\
Outlet blade angle & $66.3^{\circ}$ & $\mathrm{Ma}$ & 0.22 \\
Axial chord $C_{x}$ & $75 \mathrm{~mm}$ & $\dot{m}_{\mathrm{m}}$ & $1.13 \mathrm{~kg} \cdot \mathrm{s}^{-1}$ \\
$H_{\mathrm{NGV}} / C_{x}$ & 1.3 & $p_{\text {tot,in }} / p_{\text {out }}$ & 1.035 \\
Pitch $/ C_{x}$ & 0.884 & $\dot{m}_{\mathrm{c}} / \dot{m}_{\mathrm{m}}$ & $0,0.5,1 \%$ \\
\hline
\end{tabular}




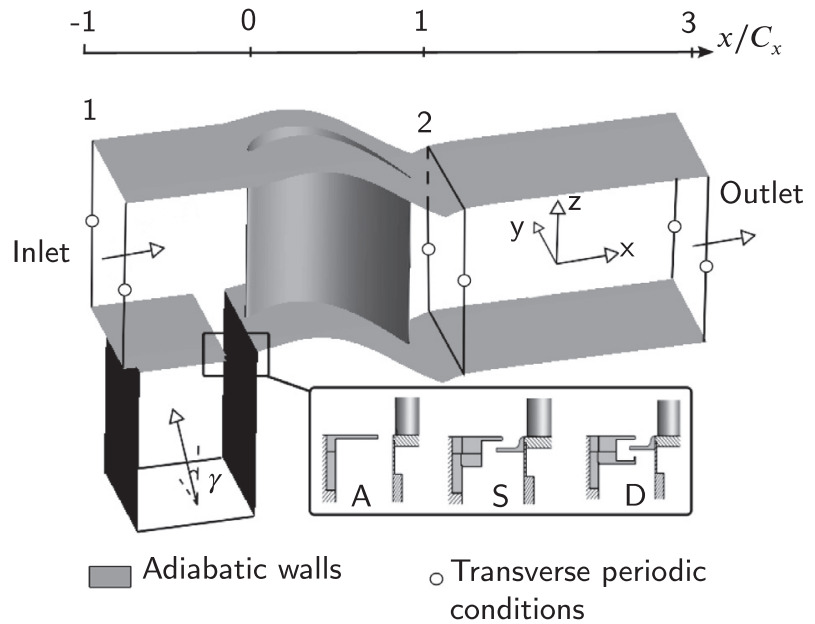

Fig. 2. Simulation domain.

noted by a letter for the rim seal geometry considered (A: axial, $\mathrm{S}$ : simple overlapping, D: double overlapping) and a figure for the purge flow rate imposed (0: 0\%, 05: 0.5\%, 1: $1 \%$ ). For example, the configuration A05 stands for the axial rim seal geometry with $0.5 \%$ of the mainstream flow supplied in the cavity. RANS simulations are performed using the CFD code elsA [2]. This software uses a cell centered approach on structured multiblock meshes. An upwind Roe scheme with third-order limiter is used for the convective terms [28]. Diffusive fluxes are computed with a secondorder centred scheme. The Wilcox $\mathrm{k}-\omega$ two-equations model with Zheng's limiter [41] is used. The LES $_{\text {turb.inj. }}$ is performed using the in-house unstructured AVBP solver [10]. The convective operator is discretized by the two-step Taylor-Galerkin scheme [5] (3rd order accurate). The Sub-Grid Scale model (SGS) is the Wall-Adapting Local Eddy-viscosity (WALE) [27]. A layer of 20 prisms in near-wall regions is applied with an expansion ratio of 1.03 and tetraedra fill the remaining domain. The meshes for RANS and LES $_{\text {turb.inj. }}$ are designed to fulfil wall-resolved requirements $[12,29,30]$ including a grid refinement from the inlet to the blade leading edge to transport turbulent structures generated at the inlet. This lead to a mesh of $7 \times 10^{6}$ cells for the RANS and $80 \times 10^{6}$ cells for the LES $_{\text {turb.inj. }}$.

The comparison against experiments and the analysis of the flow field is provided in the companion paper. A summary of the main mechanisms described in the companion paper is here proposed based on the sketch in Fig. 3 to give a clearer view of the corresponding mechanisms of loss. Due to the relatively high freestream turbulence (6\%) and for the considered Reynolds number, the boundary layer over the hub, shroud and blade is turbulent without separation on the aft portion of the blade suction side. On the pressure side, an enclosed separation bubble between 10 and $30 \%$ chord occurs. Close to the rim seal interface upstream of the blade, a shear layer is induced due to the high velocity of main annulus flow compared to the cavity flow. The main annulus flow is deviated downwards into the cavity when facing the blade due to potential effect. A mass conservation balance for the cavity shows that some cavity flow blows into mainstream at the center of the passage where pressure is lower (F). The cavity flow feeds the initiating secondary vortices in the blade passage. Secondary vortices are initiated face to the blade by the separation of the hub boundary layer that rolls up in vortices known as the horse shoe vortices. The horse shoe vortices are chopped by the blade leading edge in two main vortices: the suction side leg $(A)$ that remain close to blade suction side and a pressure side vortex (B) that travels in the passage due to the cross pressure gradient between two adjacent

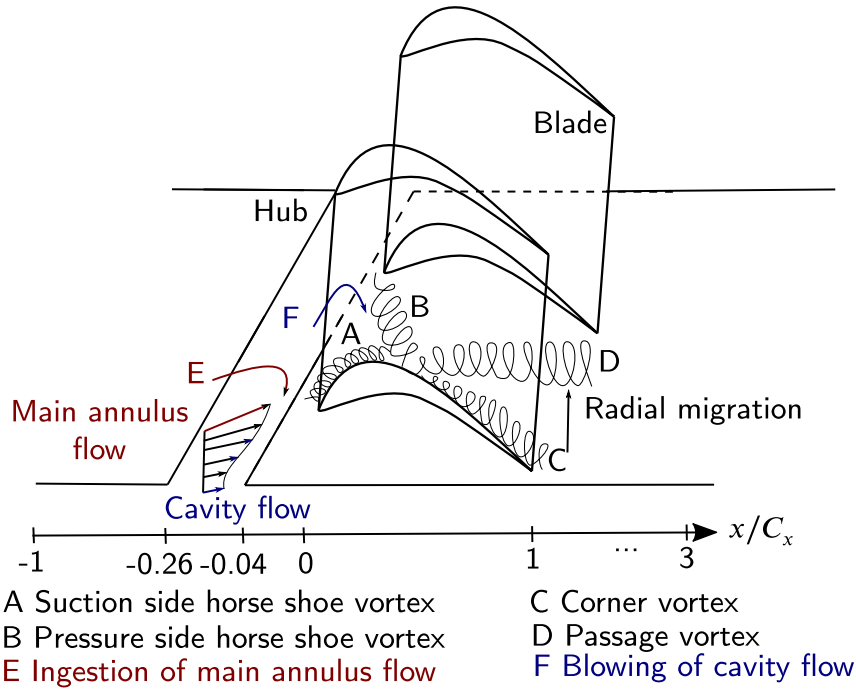

Fig. 3. Main secondary vortices observed in the linear cascade: suction side $(A)$ and pressure side leg of the horse shoe vortex (B), corner vortex $(C)$ and passage vortex (D) including the ingestion process face to the blade due to potential effect (E) and blowing of cavity flow into the annulus at the center of the passage (F).

blades and entrains the flow close to the hub and the cavity flow. These two vortices gather close to the blade suction side and initiate two main vortices: a corner vortex close to the hub and blade suction side (C) and a migrating vortex known as passage vortex (D). The same process of secondary flow development can be observed at the shroud of the configuration representing a stator row except that no feeding process of secondary vortices by cavity flow is induced.

\section{Exergy analysis in the simulation domain}

The exergy formulation is applied to the linear cascade configuration. This general assessment is first led using the RANS simulation. The RANS and LES $_{\text {turb.inj. }}$ are then compared with a splitting between mean and turbulent contribution in the emphasis to describe the differences between the two approaches from a loss generation perspective. Once compared, the $\mathrm{LES}_{\text {turb.inj. }}$ is used to describe the contributions to losses of the boundary layers over the wetted surfaces (hub, shroud and blade) and in the remaining domain (the full domain where the subdomains related to boundary layers have been removed) where secondary flows are known to develop and contribute to losses in the turbine. All these elements will be used to obtain the regions and mechanisms inducing loss in the turbine. The general transport equation for exergy $\chi$ in differential form proposed in Eq. (11) of Appendix A can be written in integral form considering the whole simulation domain and steady flow conditions.

This provides the following balance equation $[1,37]$ :

$\oiint(\rho \chi) u_{j} n_{j} d A_{\mathrm{IO}}=P_{\text {shaft }}+\chi_{q}+\Phi_{\nabla u}+\Phi_{\nabla T}$

where $A_{\mathrm{IO}}$ refers to the inlet / outlet plane of the simulation domain. This equation for exergy $\chi=\left(h_{\text {tot }}-h_{0}\right)-T_{0}\left(s-s_{0}\right)$ gives a power balance for both total enthalpy $h_{\text {tot }}$ and entropy quantities $s$ between the inlet and outlet of the domain (left-hand side of the equation). Exergy can vary due to the work transferred with the shaft $\left(P_{\text {shaft }}\right)$, power associated to the heat flux $\left(\chi_{q}\right)$, and the irreversibility generated in the domain induced by velocity gradients $\left(\Phi_{\nabla u}\right)$ and temperature gradients $\left(\Phi_{\nabla T}\right)$. Since the configuration is static, no work is transferred with the fluid similarly to a stator row leading to $P_{\text {shaft }}=0$. No heat is transferred at the bor- 


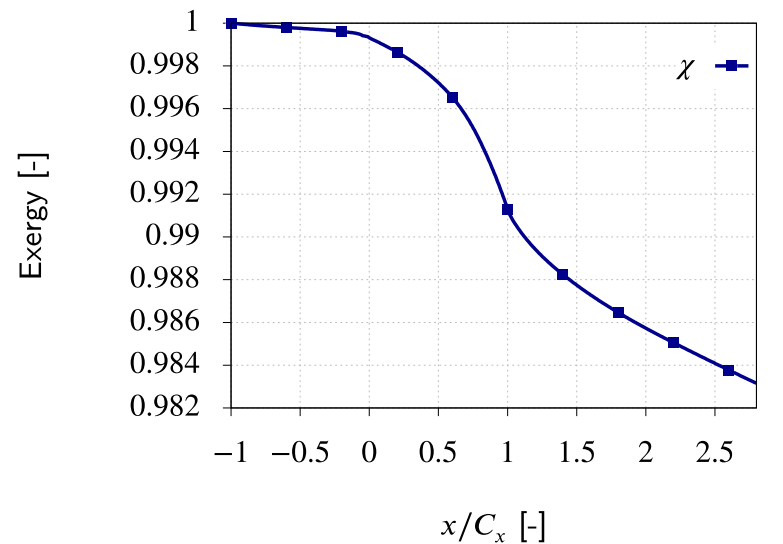

Fig. 4. Evolution of the flow exergy from the inlet to outlet of the domain (RANS), configuration A05.

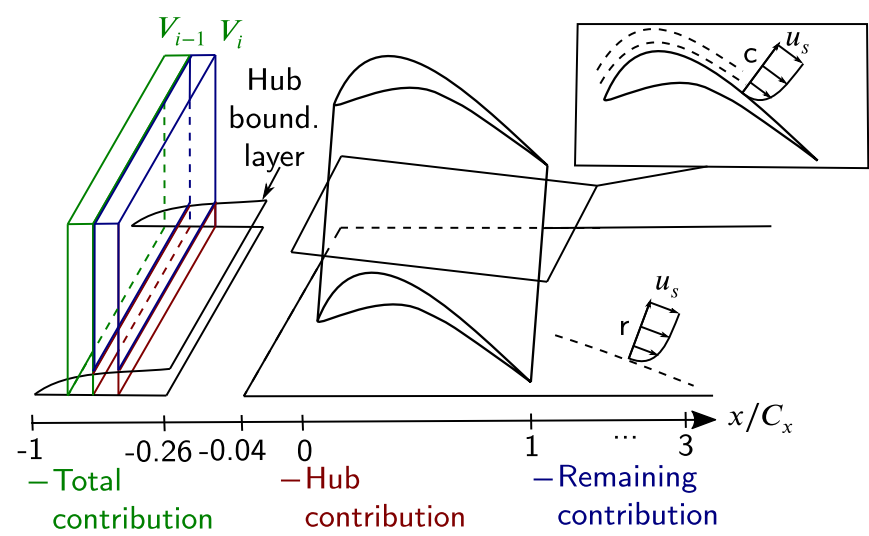

Fig. 5. Example of a simulation domain discretized in axial subvolumes $V_{i}$ (green). For a simple configuration where only the hub boundary layer is considered, $V_{i}$ can be split in a subvolume associated to the hub boundary layer (red) and a remaining domain that is simply the subvolume $V_{i}$ minus the subvolume associated to the hub boundary layer (blue). (For interpretation of the references to colour in this figure legend, the reader is referred to the web version of this article.)

der of the domain (since adiabatic wall) leading to $\chi_{q}=0$. Therefore, the exergy variation between inlet and outlet of the domain can only decrease due to viscous $\Phi_{\nabla u}$ and thermal irreversibilities $\Phi_{\nabla T}$ in the flow field. In current static configuration without heat transfer, the entropy equation is therefore sufficient to draw the exergy analysis since the total enthalpy is conserved. The viscous and thermal contributions in the RANS formalism are obtained by performing a volume integration of the velocity and temperature gradients from the inlet to the considered position $\mathrm{x}$ [26]:

$\Phi_{\nabla u}(x)=\iiint_{\mathcal{V}, 0 \rightarrow x} \overline{\tau_{i j, \mathrm{eff}}} \frac{T_{0}}{\bar{T}} \frac{\partial \overline{u_{i}}}{\partial x_{j}} \mathrm{~d} \mathcal{V}$

$\Phi_{\nabla T}(x)=\iiint_{\mathcal{V}, 0 \rightarrow x}\left(\lambda+\lambda_{\text {turb }}\right) \frac{T_{0}}{\bar{T}^{2}}\left(\frac{\partial \bar{T}}{\partial x_{j}}\right)^{2} \mathrm{~d} \mathcal{V}$

where $\tau_{i j \text {,eff }}=\left(\mu+\mu_{\text {turb }}\right)\left(\partial \overline{u_{i}} / \partial x_{j}+\partial \overline{u_{j}} / \partial x_{i}\right)$ is the effective viscous stress tensor and - the Reynolds averaged quantities as a direct output of the simulation. Fig. 4 shows the exergy decrease of the flow along the simulation domain where the environment (reference state) has been taken at conditions $\left(p_{0}=101,325 \mathrm{~Pa}\right.$, $T_{0}=300 \mathrm{~K}$ ). The inlet to rim seal left corner extends from $x / C_{x}=-$ 1 to -0.26 , rim seal region from $x / C_{x}=-0.26$ to -0.04 , blade domain from $x / C_{x}=0$ to 1 and blade trailing edge to two axial chord downstream of the blade (outlet) from $x / C_{x}=1$ to 3 (see Fig. 5). This figure is obtained by subtracting the total exergy at the inlet of the domain (here normalized to one) to the contributions

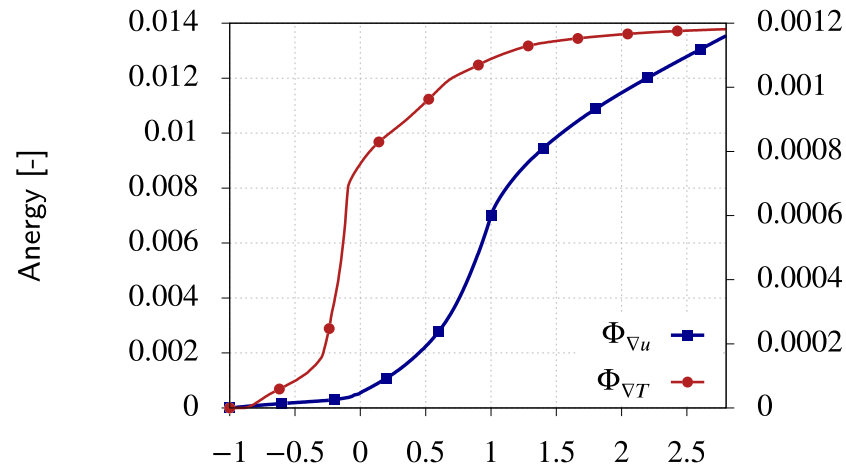

$x / C_{x}[-]$

Fig. 6. Evolution of the flow anergy from the inlet to outlet of the domain (RANS). Right-hand legend refers to thermal contribution and left-hand to viscous contribution, configuration A05.

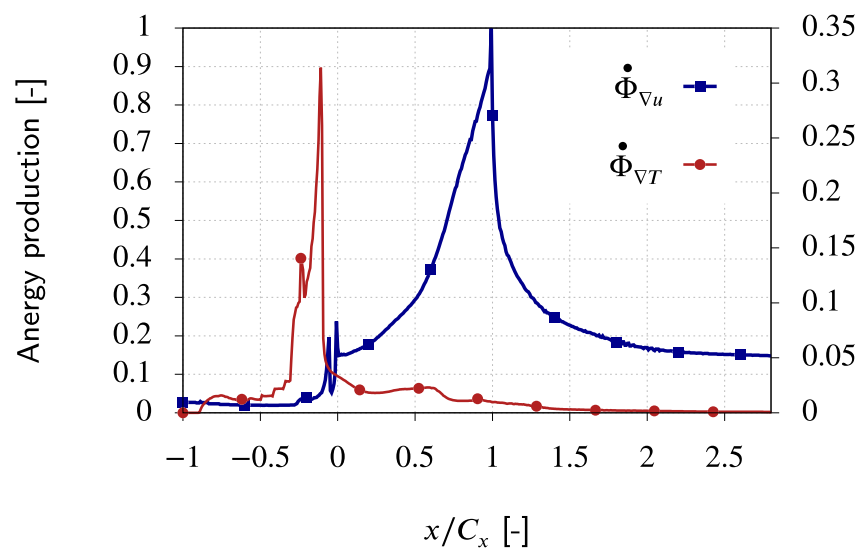

Fig. 7. Evolution of the flow anergy production from the inlet to outlet of the domain (RANS). Right-hand legend refers to thermal contribution and left-hand to viscous contribution, configuration A05.

related to velocity $\Phi_{\nabla u}$ and temperature gradients $\Phi_{\nabla T}$. The decrease of exergy due to these two contributions is generally said to produce anergy, i.e. useless energy in the purpose to generate work. The viscous and thermal anergy evolutions along the simulation domain are given in Fig. 6 where the left-hand side abscissa corresponds to viscous term and right-hand side to the thermal one. In addition, the derivative according to the axial coordinate of the anergy that is here referred to anergy production at a station $\mathrm{x}$ of the domain and denoted $\dot{\Phi}$ is provided in Fig. 7. This quantity can be obtained by splitting the whole domain in axial subdomains of characteristic length $\mathrm{dx}$ and integrating the velocity and temperature gradient terms over these subvolumes for which the characteristic length tends towards zero. For the thermal contribution, the main regions of anergy production correspond to the rim seal extent where the cold cavity flow starts to interact with hot main annulus flow and downstream along the blade. The viscous anergy production is relatively low from the inlet to the rim seal, increases sharply along the rim seal and blade extent before to return towards intermediate levels of anergy production downstream of the blade. The viscous anergy production keeps non-zero contribution downstream of the blade while the thermal contribution is almost zero as soon as one axial chord downstream of the nozzle guide vane $\left(x / C_{x}=2\right)$. The thermal contribution is in the order of magnitude of ten times lower than the viscous contribution. At the outlet of the domain, the remaining exergy is around $98.2 \%$ of the exergy available at inlet of the domain (compared 
to the reference state), i.e. the linear cascade deteriorates $1.8 \%$ by viscous and temperature dissipation process to accelerate the flow. The exergy analysis accounts for both the contributions induced by viscous and thermal mixing processes. In the remaining of this paper, the focus will be given to the viscous contribution. In the companion paper, the comparison against experiments showed that the RANS simulation is well able to recover the flow physics due to the strong influence of free-stream turbulence. However, several recent papers have shown that a detailed discussion of losses (entropy generation) can be better performed by LES [18,20,21,24]. In addition, the $\mathrm{SLES}_{\text {turb.inj. }}$ showed a fine agreement with the experiments. Therefore, the splitting between mean (laminar and turbulent contributions) will be led for both RANS and LES $_{\text {turb.inj. }}$ in order to show the differences between the two approaches from the loss generation sight while the detailed analysis of the losses generated in the linear cascade will be led using the LES $_{\text {turb.inj. }}$.

\section{RANS/LES comparison: viscous losses}

Section 3 provided the total production of viscous anergy/entropy along the simulation domain. In a turbulent flow, it corresponds to a mean contribution sometimes called laminar contribution and a turbulent one [20]. This former contribution is only due to the mean flow distortion. The second contribution is provided by turbulence that under transfer of energy from large to small scales is dissipated in internal energy (heat) that induce the non locality between mean energy flow lost and equivalent heat generated at small scales. The RANS approach provides a direct splitting between the mean contribution through the natural viscosity of the fluid $(\mu)$ and the turbulent contribution with the equivalent turbulent viscosity $\left(\mu_{\text {turb }}\right)$ [26]. The total contribution is obtained by summing the two contributions as provided in Eq. (2):

$\left[\begin{array}{c}\Phi_{\nabla u, \text { mean }} \\ \Phi_{\nabla u, \text { turb }}\end{array}\right]=\iiint_{\mathcal{V}}\left[\begin{array}{c}\mu \\ \mu_{\text {turb }}\end{array}\right]\left(\frac{\partial \overline{u_{i}}}{\partial x_{j}}+\frac{\partial \overline{u_{j}}}{\partial x_{i}}\right) \frac{T_{0}}{\bar{T}} \frac{\partial \overline{u_{i}}}{\partial x_{j}} \mathrm{~d} \mathcal{V}$.

In LES simulation, the splitting can be obtained by taking advantage of the unsteady nature of the method. The total viscous irreversibilities produced $\Phi_{\nabla \mathrm{u}}$ can be written as [19-21,23,40]:

$\Phi_{\nabla \mathrm{u}}=\Phi_{\nabla \mathrm{u}, \text { mean }}+P_{k}$

where $\Phi_{\nabla \mathrm{u} \text {,mean }}$ is the mean viscous dissipation and $P_{k}$ is the Turbulent Kinetic Energy (TKE) production term. These different contributions can be expressed as:

$\Phi_{\nabla \mathrm{u}, \text { mean }}=\iiint_{\mathcal{V}}\left(\mu+\mu_{\mathrm{SGS}}\right)\left(\frac{\partial \overline{u_{i}}}{\partial x_{j}}+\frac{\partial \overline{u_{j}}}{\partial x_{i}}\right) \frac{T_{0}}{\bar{T}} \frac{\partial \overline{u_{i}}}{\partial x_{j}} d \mathcal{V}$

$P_{k}=\iiint_{\mathcal{V}}-\overline{u_{i}^{\prime} u_{j}^{\prime}} \frac{\partial \overline{u_{i}}}{\partial x_{j}} d \mathcal{V}$

where $\mu_{\mathrm{SGS}}$ is the equivalent sub-grid scale viscosity and - represents here the temporal averaging operator. For the RANS and

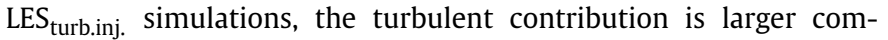
pared to the mean one and the two approaches exhibit similar trends of loss generation along the simulation domain (see Fig. 8). Some differences can be exhibited between the two approaches: a decay of turbulent contribution can be observed for the $\mathrm{LES}_{\text {turb.inj. }}$ from the inlet to the blade leading edge (between $x / C_{x}=-1$ and $x / C_{x}=0$ ) that can be associated to the decay of turbulent structures injected at the inlet of the domain while not observed in RANS. At the rim seal interface, the production of loss is stronger for the RANS with a steep increase that may be induced by an overestimate of turbulent contribution compared to the LES turb.inj. Downstream of the blade, the decrease of turbulent contribution for LES $_{\text {turb.inj. }}$ is made over a lower axial extent compared to RANS that may be due to a transport of the turbulent wake over a longer distance for the RANS.

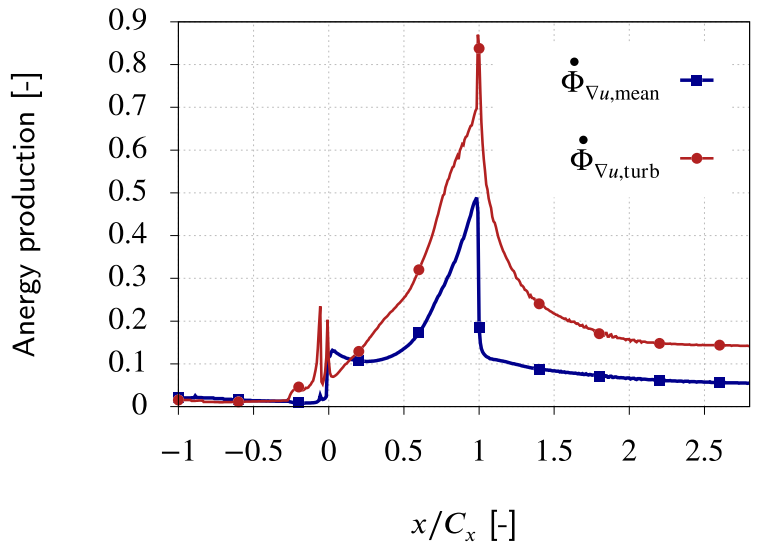

(a)

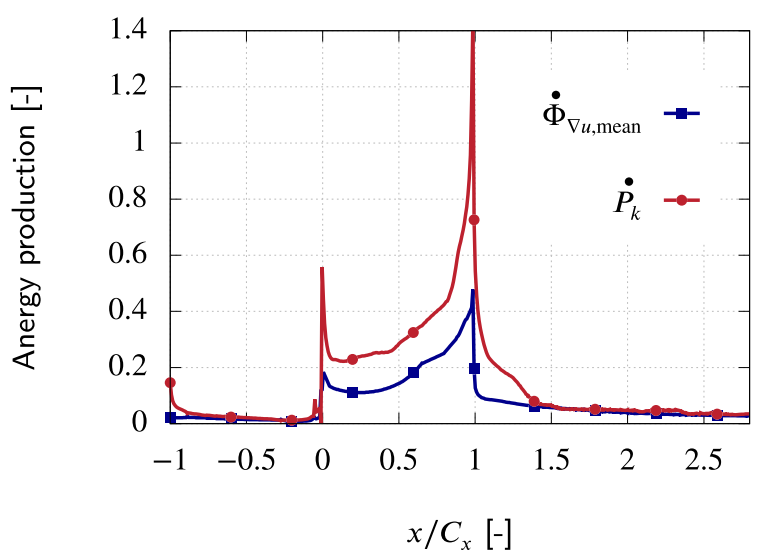

(b)

Fig. 8. Evolution of the viscous anergy production $d \Phi_{\nabla u} / d x$ along the simulation including the mean and turbulent contributions for the RANS (a) and TKE production $P_{k}$ for LES $_{\text {turb.inj. }}$ simulation (b), configuration A05.

\section{Boundary layer and secondary flow losses}

Based on the boundary layer edge detection method $[4,6]$, the boundary layer thickness can be obtained for the different wetted surfaces of the domain (hub, shroud and blade) and the corresponding volumes $\mathcal{V}_{\text {hub }}, \mathcal{V}_{\text {shroud }}, \mathcal{V}_{\text {blade. }}$ The full simulation domain less the boundary layer contributions provides the remaining domain with an associated volume $\mathcal{V}_{\text {rem. }}$ term. The exergy analysis is applied to these restricted domains to obtain the contributions of the different boundary layers and the remaining domain in a similar manner to previous studies of the losses in gas turbines $[7,8,14,21]$. The different figures related to the contributions of the boundary layers and remaining domain are given in conjunction with the total contribution of the domain at a same abscissa denoted $\dot{\Phi}_{\nabla u \text {,tot }}$ to give the reader the magnitude of the contribution to the total one. In addition, since the viscous anergy production is the sum of velocity gradients (see Eq. (6)), the main gradients directions contributing to the generation of losses can be obtained. These gradients can be expanded in any coordinate system and in current study the local streamline coordinate (i.e. the Cartesian main axis is oriented with the stream direction in any points) is used. The wall-normal contributions to boundary layers on curved surfaces (blade) can be directly obtained and the cross contributions can be used to provide the contribution associated to secondary vortices [42]. Fig. 9 shows the viscous anergy production related to the boundary layers on the different wetted surfaces (hub, shroud and blade) and the remaining term. The viscous 


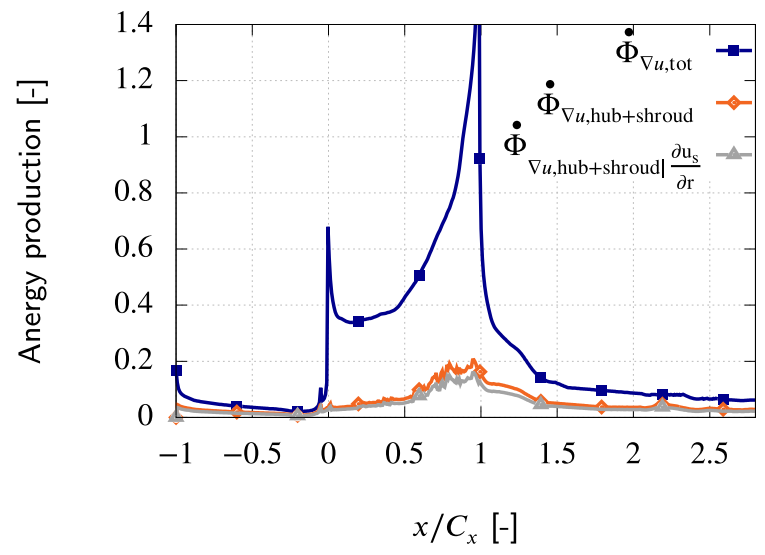

(a)

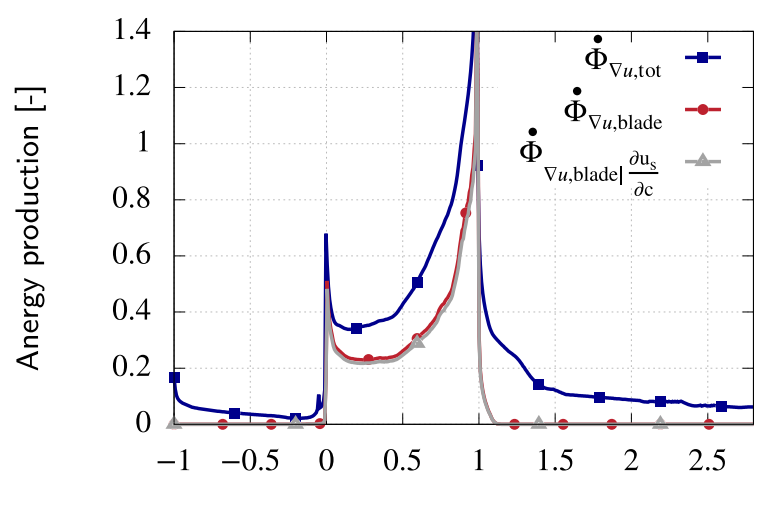

$x / C_{x}[-]$

(b)

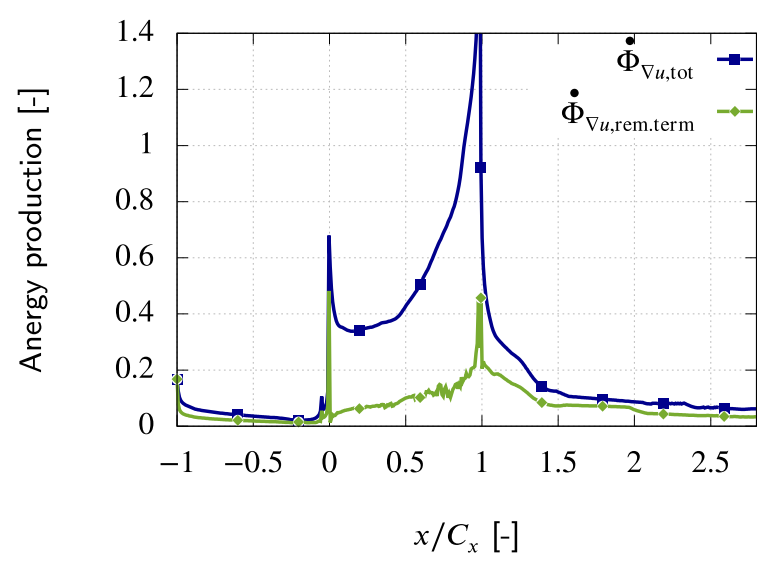

(c)

Fig. 9. Viscous anergy production for the different subdomains based on the LES $_{\text {turb.inj. }}$ configuration A05.

anergy production restricted to particular velocity gradients that includes both laminar and turbulent contributions is also provided in same figures. The area under the different curves of Fig. 9 provides the different contributions to the total losses generated: the hub/shroud boundary layers contribute to $25 \%$ of losses, $38 \%$ for the blade boundary layer and $37 \%$ for the remaining domain. For the hub and shroud, the contribution to losees is almost constant along the simulation domain with an increase along the blade extent between $x / C_{x}=0$ and 1 . This can be associated to the development of a boundary layer over the hub and shroud that in-

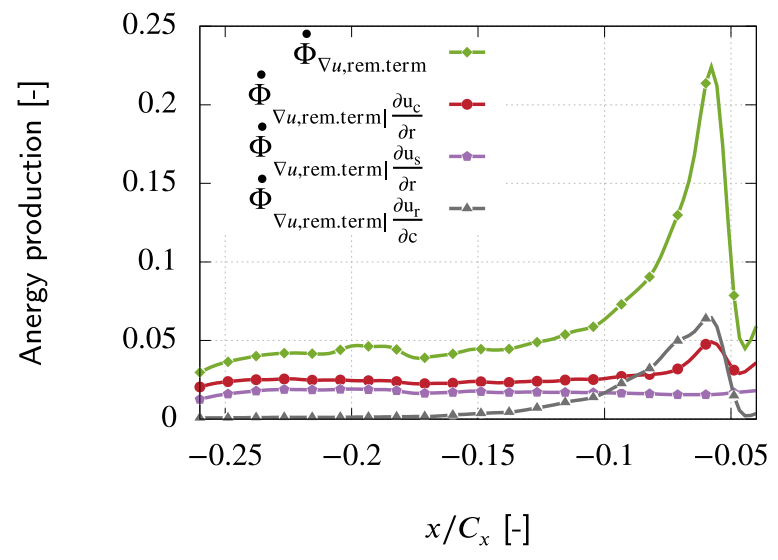

Fig. 10. Anergy production at the rim seal interface in the remaining domain based on the LES $_{\text {turb.inj. }}$, configuration A05.

duce velocity gradients close to the wall and as a consequence viscous anergy. This contribution being induced by the hub/shroud wall-normal gradient $\left(\partial \mathrm{u}_{s} / \partial \mathrm{r}\right.$, see Fig. 9a). Along the blade extent, the blade boundary layer is a strong contribution to losses. Similarly to hub and shroud boundary layers, these losses are related to the wall-normal velocity gradients associated to the blade boundary layer $\left(\partial \mathrm{u}_{s} / \partial \mathrm{c}\right.$, see Fig. $\left.9 \mathrm{~b}\right)$. Wheeler et al. [40] reported similar loss profiles along the domain in the DNS of a high-pressure turbine vane with a strong contribution of the mean strain rate along the blade extent associated to the blade boundary layer. The increase of the blade boundary layer losses on the aft portion of the blade was also observed by Lengani et al. [21] in the LES of a low-pressure turbine with passing wakes where the increase of losses was attributed to small turbulent scales promoted by upstream wakes. Hammer et al. [14] also reported similar influence of the rear part of the blade and the strong sensitivity of losses to the boundary layer state and/or potential boundary layer separation on the blade suction side. In the remaining domain (see Fig. 9c), several physical phenomena can be identified and contribute to the generation of losses. From the inlet $x / C_{x}=-1$ to the rim seal left corner $x / C_{x}=-0.26$, the anergy production can be associated to the dissipation of turbulent structures injected at the inlet of the domain. At the rim seal interface extending between $x / C_{x}=-0.26$ and $x / C_{x}=-0.12$, the anergy production is related to the axial and tangential velocity gradient in the radial direction $\left(\partial \mathrm{u}_{s} / \partial \mathrm{r}\right.$ and $\left.\partial \mathrm{u}_{c} / \partial \mathrm{r}\right)$ between high-momentum main annulus flow and low-momentum cavity flow (see Fig. 10). Close to rim seal right corner between $x / C_{x}=-0.12$ and -0.04 , the anergy production strongly increases. This contribution is induced by the variations of radial velocity in the tangential direction. This corresponds to the ingestion process of main annulus flow face to the blade (negative radial velocity) while the cavity flow emerges close to the center of the passage (positive radial velocity). The losses associated to the remaining domain in the inter-blade channel between $x / C_{x}=0$ and $x / C_{x}=1$ can be attributed to secondary vortices: pressure and suction side of the horse shoe vortex, passage and corner vortices downstream the merging point of pressure and suction side leg. These vortices are continuously fed by the cross flow component induced by the blade-to-blade pressure gradient. The energy provided by the cross pressure gradient is mainly stored into transverse energy terms to the main direction of the vortices. The vortices dissipate this secondary kinetic energy (energy contained in the cross contributions to the stream one) under a mixing process. In addition, a major contribution to losses of secondary vortices in the passage is induced by strong variations of radial velocity according to the stream and cross component. The passage 


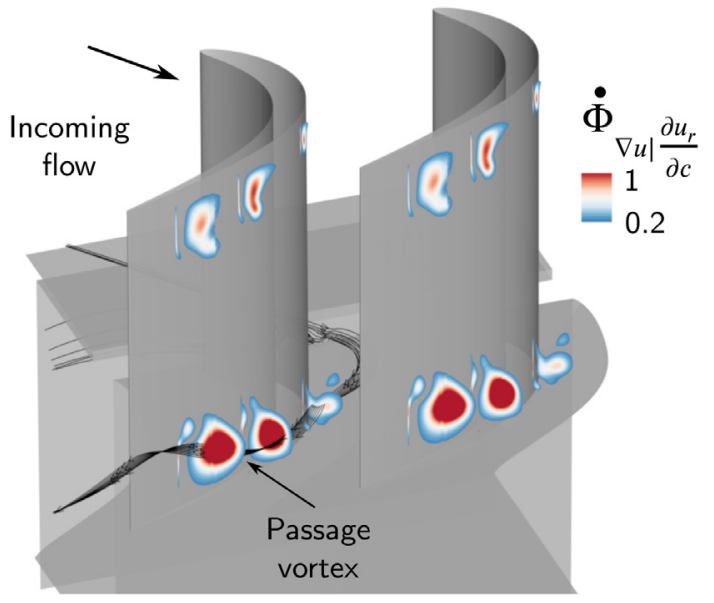

Fig. 11. Axial cuts in the passage colored by viscous anergy production related to $\partial u_{r} / \partial c$ gradients, configuration A05.

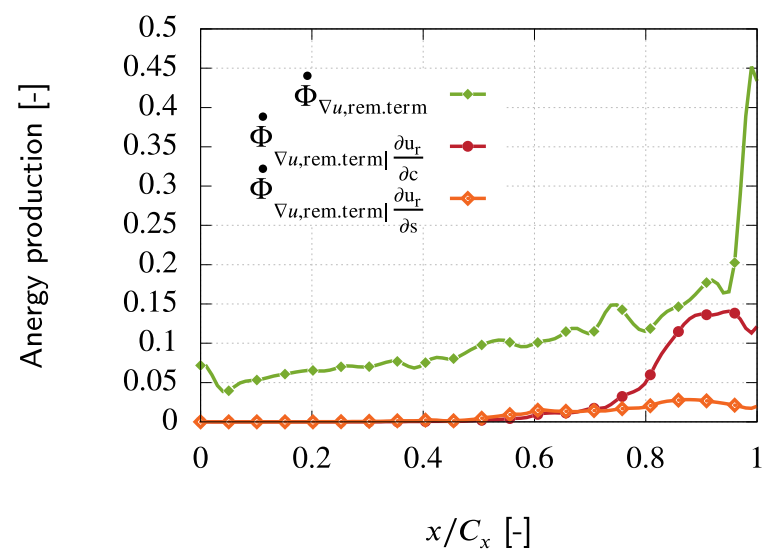

Fig. 12. Viscous anergy production along the blade extent in the remaining domain based on the LES turb.inj., configuration A05.

vortex migrating close to the blade suction side serves as a region of blockage. In a similar manner to a nozzle, this enforces the flow in the inter-blade channel to migrate radially. This phenomenon induces strong variation of radial velocity components in the stream and cross direction direction $\left(\partial u_{r} / \partial s\right.$ and $\partial u_{r} / \partial c$ gradients, see Fig. 11). The resulting interaction between this radial flow and the passage vortex is not purely a potential flow effect, and shearing occurs between the two flow features that can be also observed in current configuration (see Fig. 12 between $x / C_{x}=0.6$ and $x / C_{x}=1$ ). This phenomenon was originally observed by Zlatinov [42]. The third mechanism of loss associated to the secondary vortices in the passage is the additional friction on the hub, shroud and blade suction surfaces where the secondary vortices travel (see Fig. 13). This phenomenon was initially observed by Denton and Pullan [8] studying the endwall sources of loss based on an entropy formulation. Downstream of the blade from $x / C_{x}=1$ to $x / C_{x}=3$, the losses associated to the remaining domain progressively decay. The main contributions to the decay downstream of the trailing edge is twofold: a first contribution related to cross velocity gradients $\left(\partial u_{s} / \partial c\right.$ and $\left.\partial u_{c} / \partial s\right)$. The cross velocity gradient corresponds to the shear layer between the suction and pressure side flow promoting the formation of trailing shed vortices. The contribution is strong close to the trailing edge with a quick decay since becoming almost zero as soon as $x / C_{x}=1.4$. A second process related to the passage vortex decay that induces entropy production due to a variation of radial velocity $\left(\partial u_{r} / \partial c\right)$ that is performed

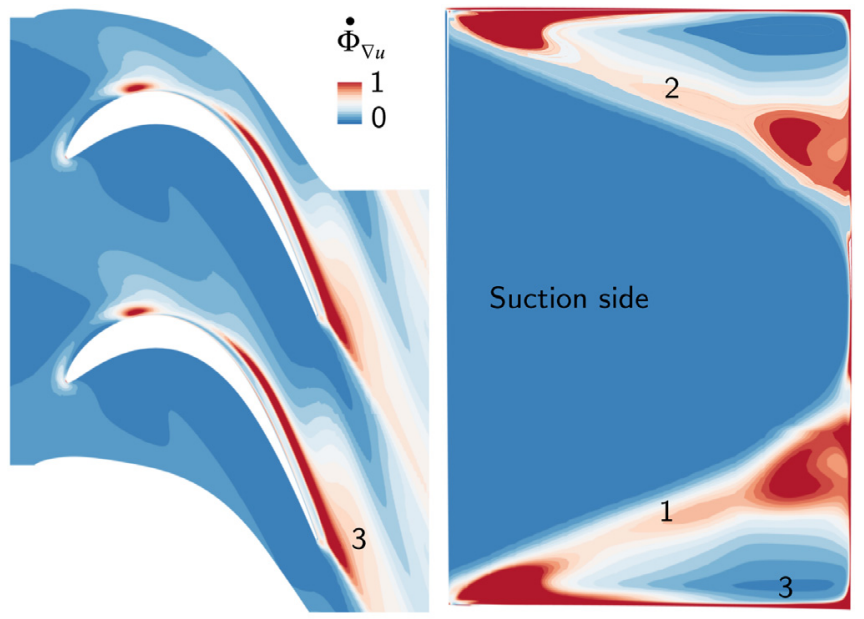

1 Hub passage vortex

2 Shroud passage vortex

3 Corner vortex

Fig. 13. Viscous anergy production in the boundary layer at a constant distance from the wall $\left(y^{+}=30\right)$ for the hub (left) and blade (right) based on the LES $_{\text {turb.inj., }}$, configuration A05.

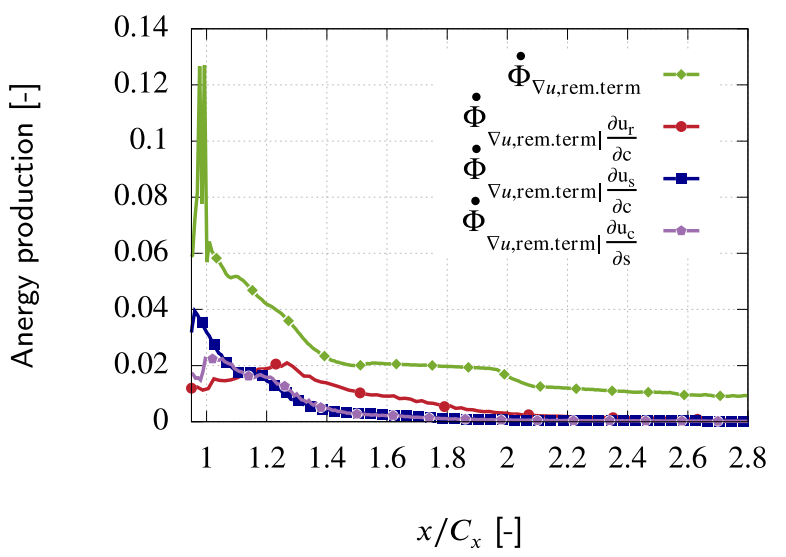

Fig. 14. Viscous anergy production downstream of the blade in the remaining domain based on the LES turb.inj. configuration A05.

over a longer distance since becoming negligible downstream of $x / C_{x}=1.8-2$ (see Fig. 14).

\section{Influence of purge flow rate on viscous anergy production}

The influence of purge flow rate on the anergy production is analyzed by applying the exergy analysis developed in previous Section 5 to the LES $_{\text {turb.inj. }}$ performed at the different purge flow rates available $(0,0.5$ and $1 \%$ of the main flow rate). The losses associated to the shroud boundary layer have been checked to be unmodified by the amount of purge flow. Indeed, for conventional purge flow rates (typically $1 \%$ of the main annulus flow rate), the influence of purge flow rate is limited to the first half height of the main annulus [36]. The main influence of purge flow rate is observed on the hub and remaining domain contribution (see Fig. 15a and b). The purge flow rate increases anergy production in the blade passage from $x / C_{x}=0$ to $x / C_{x}=1$ and downstream of the blade. As stated, the anergy generated in the passage out of the boundary layers and downstream of the blade in the remaining domain may be attributed to secondary flows developing in the passage. The current observation supports a feeding process of the secondary vortices in the passage by purge flow that as a consequence generates more anergy. Due to more energetic sec- 


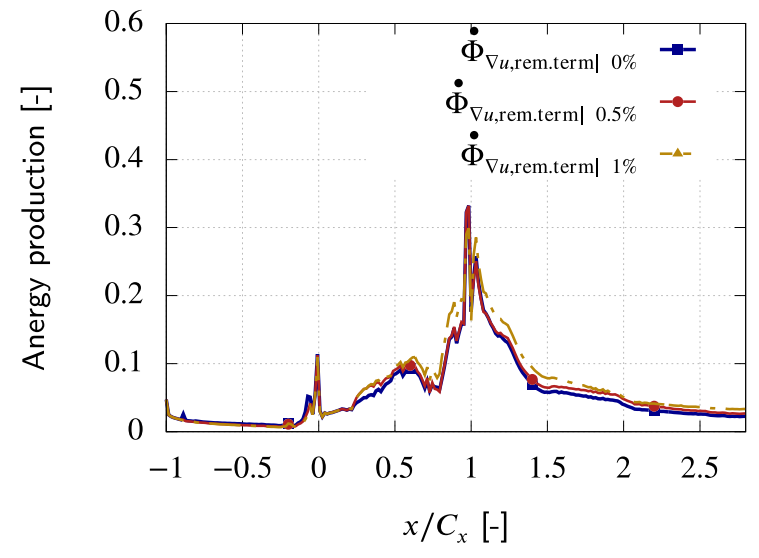

(a)

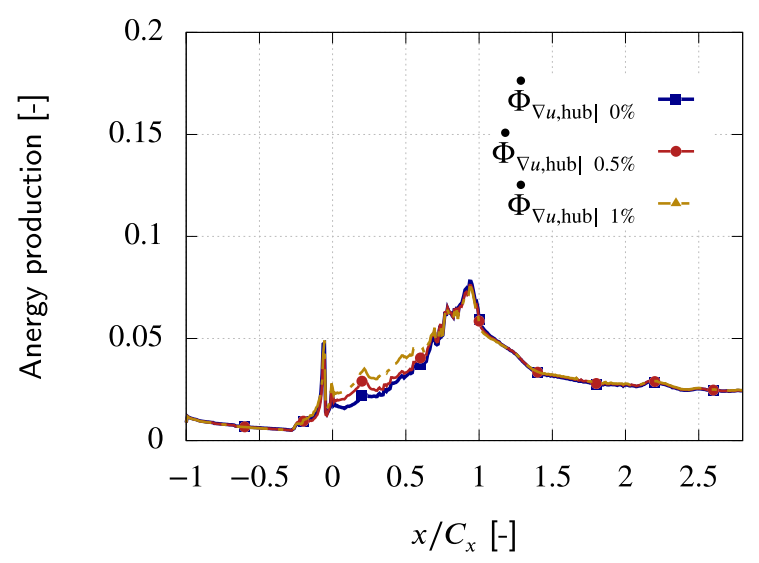

(b)

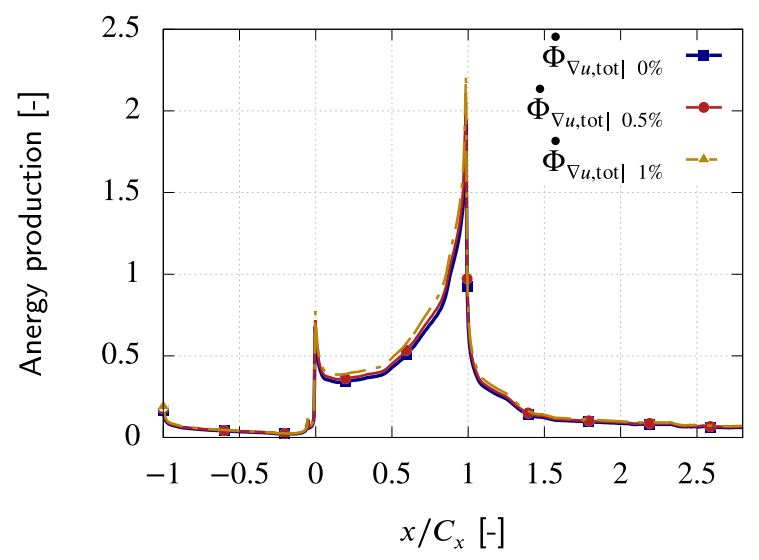

(c)

Fig. 15. Influence of the purge flow rate on viscous anergy production for the hub (a) remaining domain (b) and total contributions (c) based on the LES $_{\text {turb.inj., axial }}$ rim seal.

ondary vortices, the friction process at the hub is also higher with a higher purge flow amount. As a consequence, the total anergy produced along the domain increases with an increased purge flow rate (see Fig. 15c) which is compliant with studies dealing with the influence of purge flow rate on the losses generated in turbines $[11,31,33]$.

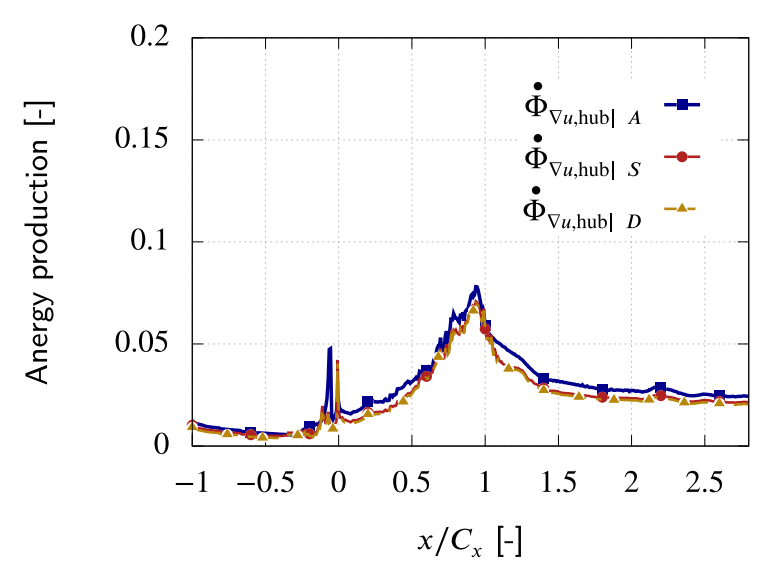

(a)

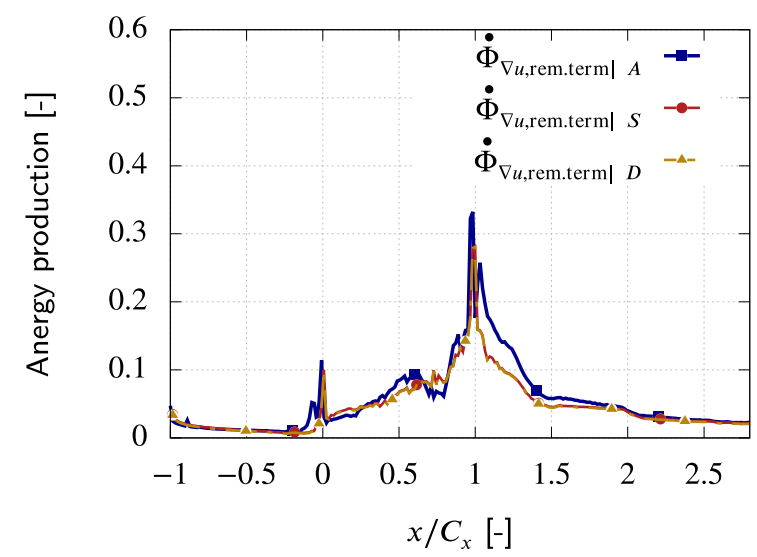

(b)

Fig. 16. Influence of the rim seal geometry (axial, simple and double overlapping) on viscous anergy production for the hub (a) and remaining domain (b) contributions based on the $\mathrm{LES}_{\text {turb.inj. }}$, intermediate purge flow rate.

\section{Influence of rim seal geometry on anergy production}

At the rim seal interface, the anergy production associated to azimuthal and axial velocity gap between the main and rim seal flow is lower for the overlapping geometries. This is due to the local recirculation zone for overlapping geometries that reduces the shear compared to the axial geometry (see Fig. 16a). The overlapping geometries promote an intense recirculation zone that homogenize the flow at the rim seal interface. A main consequence is that the cavity purge flow blows earlier at the rim seal interface, i.e. at a lower axial coordinate for the axial rim seal compared to the overlapping geometries (see positive radial velocity at the rim seal interface for axial and simple overlapping geometry in Fig. 17). This induces an earlier development and strengthening of the horse shoe vortex process, pressure side of the horse shoe vortex process by purge flow for axial geometry compared to overlapping ones (see Fig. 18 where the purge flow can be tracked since injected at a lower temperature). The radial migration of secondary vortices along blade suction are initiated early for the axial rim seal geometry and promote secondary vortices with a larger detrimental impact on losses compared to axial overlapping geometries.

\section{Conclusion}

This paper has been devoted to the analysis of the losses generated in a linear cascade with an upstream cavity representative of a low-pressure turbine based on an exergy analysis. RANS and 


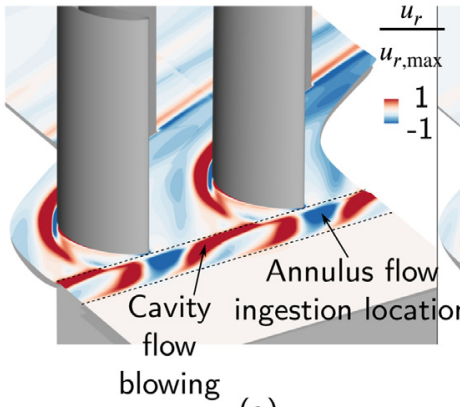

(a)

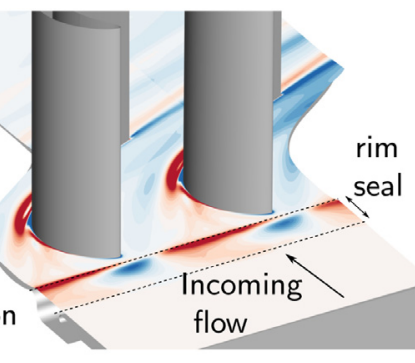

(b)
Fig. 17. Radial cut close to the hub colored by the normalized radial velocity $\mathbf{u}_{r}$ for axial A (a) and simple overlapping S geometry (b).

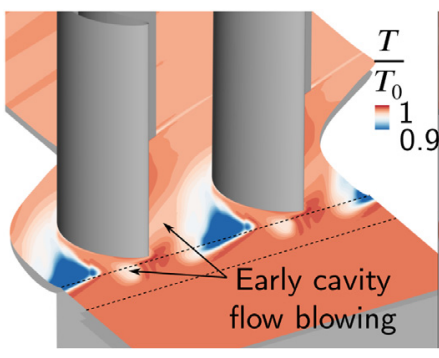

(a)

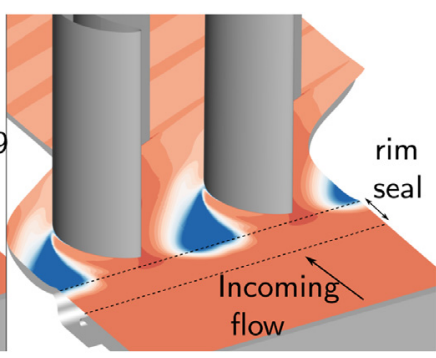

(b)
Fig. 18. Radial cut close to the hub colored by temperature for axial A (a) and simple overlapping geometry S (b).

LES with inlet turbulence injection have been compared based on this approach: the losses related to the decay of turbulent structures at the inlet are not observed in the RANS. At the rim seal interface, the losses related to the shear are triggered with a higher magnitude in RANS compared to the LES with inlet turbulence injection and the trailing edge losses are smoothed over a larger axial extent for the RANS. The hub, shroud and blade boundary layer represent around $2 / 3$ of the losses generated in the cascade due to wall-normal velocity gradients. In the remaining domain that represent around $1 / 3$ of the loss generated, several mechanisms of loss have been identified: the decay of free-stream turbulence from the inlet to blade leading edge. At the rim seal interface, the shear layer between the cavity with low momentum flow and the main annulus flow with high momentum (both axial and azimuthal) induces additional losses. Thermal anergy is also produced since the cavity flow with slightly lower temperature mixes with higher temperature main annulus flow. In the blade passage, secondary flows induce losses under various mechanisms: a friction process on the wetted surfaces where secondary vortices travel, a blockage effect due to the passage vortex promoting strong cross radial velocity gradients, and a mixing process dissipating secondary kinetic energy. Downstream of the blade leading edge, mainly two contributions are added to the hub and shroud boundary layer: the turbulent vortex shedding process that is significant until half chord downstream of the blade trailing edge. A second contribution related to the decay of secondary vortices over one axial chord length. The study of the different purge flow rates available showed that the cavity purge flow emerging in the main annulus is supplied to secondary vortices and more losses are incurred due to more energetic structures with an increased purge flow rate. Regarding the rim seal geometries, the axial overlapping geometries promote a delayed development and feeding process of secondary vortices that induce less losses generated compared to simple axial gaps.

\section{Declaration of Competing Interest}

The authors declare that they have no known competing financial interests or personal relationships that could have appeared to influence the work reported in this paper.

\section{Acknowledgements}

The authors are thankful to Safran Aicraft Engines for technical support and having funded this research project, to ONERA for licensing Cerfacs to use code elsA (ONERA-Airbus-Safran property). Numerical post-processing have been performed using the free python-based Library Antares. Part of this work was performed using HPC resources from GENCI-CCRT-CINES-IDRIS (Grant 2018A0042A06074). Experimental data were obtained within the European research project Main Annulus Gas Path Interactions (MAGPI), AST5-CT-2006-030874.

\section{Appendix A. Energy available in the purpose to generate work (exergy)}

In gas turbine application, the common quantity to deal with variation of energy in the flow is the total enthalpy $h_{\text {tot }}$ that that is the total energy ( $\left.E_{\text {tot }}\right)$ of the flow including the energy related to pressure work $h_{\text {tot }}=E_{\text {tot }}+p / \rho$. A transport equation can be derived for total enthalpy $h_{\text {tot }}$ and entropy $s$ that can be written as [13]:

$$
\begin{aligned}
& \frac{\partial\left(\rho h_{\mathrm{tot}}\right)}{\partial t}+\frac{\partial\left(\rho h_{\mathrm{tot}}\right)}{\partial x_{j}}=\frac{\partial}{\partial x_{j}}\left(\tau_{i j} u_{j}-q_{j}\right)+\frac{\partial p}{\partial t} \\
& \frac{\partial(\rho s)}{\partial t}+\frac{\partial\left(\rho s u_{i}\right)}{\partial x_{i}}+\frac{\partial\left(q_{i} / T\right)}{\partial x_{i}}=\frac{1}{T} \tau_{i j} \frac{\partial u_{i}}{\partial x_{j}}+\frac{\lambda}{T^{2}}\left(\frac{\partial T}{\partial x_{i}}\right)^{2}+\frac{\dot{Q}}{T}
\end{aligned}
$$

where $\dot{Q}$ is an internal heat source. Exergy is defined as a composite quantity between the total enthalpy of the flow that measure the total energy in the flow less the entropy contribution that measure the level of irreversibility in the flow, i.e. the amount of energy to be subtracted to the total enthalpy. Exergy is defined relatively to a dead state noted 0 since the processes of energy transfer between the flow and a gas turbine occurs in a surrounding environment (generally the atmosphere) that contains energy (since under pressure $p_{0}$ ) and with non-zero temperature $T_{0}$ but with no access to this energy in real processes. Exergy $\chi$ can be expressed as:

$\chi=\left(h_{\mathrm{tot}}-h_{0}\right)-T_{0}\left(s-s_{0}\right)$.

Based on the transport equations for total enthalpy Eq. (8) and entropy Eq. (9), a transport equation can be derived for exergy [9] without internal heat source that yields to:

$$
\begin{aligned}
\frac{\partial(\rho \chi)}{\partial t} & +\frac{\partial\left(\rho \chi u_{j}\right)}{\partial x_{j}}=\frac{\partial}{\partial x_{j}}\left(\tau_{i j} u_{j}-\left(1-\frac{T_{0}}{T}\right) q_{j}\right)-\frac{T_{0}}{T} \tau_{i j} \frac{\partial u_{i}}{\partial x_{j}} \\
& -\frac{\lambda T_{0}}{T^{2}}\left(\frac{\partial T}{\partial x_{i}}\right)^{2}+\frac{\partial p}{\partial t} .
\end{aligned}
$$

\section{References}

[1] Arntz A. Civil Aircraft aero-thermo-propulsive performance assessment by an exergy analysis of high-fidelity CFD-RANS flow solutions; 2014. Ph.D. thesis.

[2] Cambier L, Veuillot J. Status of the elsA software for flow simulation and multidisciplinary applications. In: 46th AIAA aerospace sciences meeting and exhibit; 2008. p. 664. doi:10.2514/6.2008-664.

[3] Chupp RE, Hendricks RC, Lattime SB, Steinetz BM. Sealing in turbomachinery. J Propul Power 2006;22(2):313-49. doi:10.2514/1.17778.

[4] Cliquet J, Houdeville R, Arnal D. Application of laminar-turbulent transition criteria in Navier-Stokes computations. AIAA J 2008;46(5):1182-90. doi:10.2514/1. 30215. 
[5] Colin O, Rudgyard M. Development of high-Order Taylor-Galerkin schemes for LES. J Comput Phys 2000;162(2):338-71. doi:10.1006/jcph.2000.6538.

[6] Cousteix J. Three-Dimensional and unsteady boundary-Layer computations. Annu Rev Fluid Mech 1986. doi:10.1146/annurev.fluid.18.1.173.

[7] Denton JD. Loss mechanisms in turbomachines. J Turbomach 1993;115(4):621. doi:10.1115/1.2929299.

[8] Denton JD, Pullan G. A numerical investigation into the sources of endwall loss in axial flow turbines. In: Volume 8: Turbomachinery, Parts A, B, and C; 2012. p. 1417. ISBN 978-0-7918-4474-8. doi:10.1115/GT2012-69173.

[9] Dunbar WR, Lior N, Gaggioli RA. The component equations of energy and exergy. J Energy Resour Technol 2008. doi:10.1115/1.2905924.

[10] Gicquel LYM, Gourdain N, Boussuge J-F, Deniau H, Staffelbach G, Wolf P, et al. High performance parallel computing of flows in complex geometries. Comptes Rendus Mécanique 2011;339(2-3):104-24. doi:10.1016/j.crme.2010.11.006.

[11] Girgis S, Vlasic E, Lavoie JP, Moustapha SH. The effect of secondary air injection on the performance of a transonic turbine stage. American society of mechanical engineers, international gas turbine institute, turbo expo (Publication) IGTI; 2002. doi:10.1115/GT2002-30340.

[12] Gourdain N, Sicot F, Duchaine F, Gicquel L. Large eddy simulation of flows in industrial compressors: a path from 2015 to 2035. Phil Trans R Soc A 2014;372(2022):20130323. doi:10.1098/rsta.2013.0323.

[13] Greitzer EM, Tan CS, Graf MB. Internal flow: concepts and applications (vol. 3).. Cambridge; 2007. doi:10.1017/СB09780511616709.

[14] Hammer F, Sandham N, Sandberg R. The influence of different wake profiles on losses in a low pressure turbine cascade. Int J Turbomach PropulPower 2018. doi:10.3390/ijtpp3020010.

[15] Horlock JH, Young JB, Manfrida G. Exergy analysis of modern fossil-Fuel power plants. J Eng Gas Turbine Power 2002. doi:10.1115/1.483170.

[16] Hourmouziadis J. Aerodynamic design of low pressure turbines. AGARD Lect Ser 1989;167(167).

[17] Kost F, Nicklas M. Film-cooled turbine endwall in a transonic flow field: part I - Aerodynamic measurements. J Turbomach 2001;123(4):709-19. doi:10.1115/ 1.1400112.

[18] Leggett J, Richardson E, Priebe S, Shabbir A, Michelassi V, D SR. Loss analysis of unsteady turbomachinery flows based on the mechanical work potential. ASME 2019 Turbo Expo, Phoenix, Arizona; 2019.

[19] Lengani D, Simoni D, Ubaldi M, Zunino P, Bertini F. A POD-Based procedure for the split of unsteady losses of an LPT cascade. Int J Turbomach PropulPower 2017. doi:10.3390/ijtpp2040017.

[20] Lengani D, Simoni D, Ubaldi M, Zunino P, Bertini F, Michelassi V. Accurate estimation of profile losses and analysis of loss generation mechanisms in a turbine cascade. J Turbomach 2017;139(12):121007. doi:10.1115/1.4037858.

[21] Lengani D, Simoni D, Pichler R, Sandberg RD, Michelassi V, Bertini F. Identification and quantification of losses in a LPT cascade by POD applied to LES data. Int J Heat Fluid Flow 2018. doi:10.1016/j.ijheatfluidflow.2018.01.011.

[22] Marini R., Girgis S.. The effect of blade leading edge platform shape on upstream disk cavity to mainstream flow interaction of a high-pressure turbine stage. 2009, 10.1115/gt2007-27429

[23] Michelassi V, Wissink JG. Turbulent kinetic energy production in the vane of a low-pressure linear turbine cascade with incoming wakes. Int J Rotating Mach 2015. doi:10.1155/2015/650783.

[24] Michelassi V, Chen L, Pichler R, Sandberg R, Bhaskaran R. High-Fidelity simulations of low-Pressure turbines: effect of flow coefficient and reduced frequency on losses. J Turbomach 2016. doi:10.1115/1.4033266.
[25] Moore A. Gas turbine engine internal air systems: a review of the requirements and the problems. ASME 1975 winter annual meeting: GT Papers, Houston, Texas, USA; 1975. ISBN 978-0-7918-8000-5. doi:10.1115/75-WA/GT-1. V001T01A001

[26] Moore J, Moore JG. Entropy production rates from viscous flow calculations: Part I - a turbulent boundary layer flow. Volume 1: Turbomachinery; 1983. ISBN 978-0-7918-7951-1. doi:10.1115/83-GT-70. V001T01A032

[27] Nicoud F, Ducros F. Subgrid-scale stress modelling based on the square of the velocity gradient tensor. Flow Turbul Combust 1999;62(3):183-200. doi:10 1023/A:1009995426001.

[28] Nishikawa H, Rad M, Roe P. A third-order fluctuation splitting scheme that preserves potential flow. In: 15th AIAA computational fluid dynamics conference; 2013. https://doi.org/10.2514/6.2001-2595.

[29] Pichler R, Zhao Y, Sandberg RD, Michelassi V, Pacciani R, Marconcini M, et al LES and RANS analysis of the end-wall flow in a linear LPT cascade with variable inlet conditions, Part I: Flow and secondary vorticity fields. In: ASME turbo expo 2018: turbomachinery technical conference and exposition, Oslo, Norway; 2018. https://doi.org/10.1115/GT2018-76450.

[30] Piomelli U. Wall-layer models for large-eddy simulations. Prog Aerosp Sci 2008;44(6):437-46. doi:10.1016/j.paerosci.2008.06.001.

[31] Popović I, Hodson HP. Aerothermal impact of the interaction between hub leakage and mainstream flows in highly-Loaded high pressure turbine blades. J Turbomach 2013;135(6):61014. doi:10.1115/1.4023621.

[32] Rabs M, Benra F-K, Dohmen HJ, Schneider O. Investigation of Flow Instabilities Near the Rim Cavity of a 1.5 Stage Gas Turbine. In: Volume 3: Heat Transfer, Parts A and B. ASME; 2009. p. 1263-72. doi:10.1115/GT2009-59965.

[33] Reid K, Denton JD, Pullan G, Curtis E, Longley J. The effect of stator-Rotor hub sealing flow on the mainstream aerodynamics of a turbine. ASME Conf Proc 2006;2006(4241X):789-98. doi:10.1115/GT2006-90838.

[34] Sagaut P.. Large eddy simulation for incompressible flows: an introduction. 2006. 10.1007/b137536

[35] Sandberg RD, Michelassi V. The current state of high-Fidelity simulations for main gas path turbomachinery components and their industrial impact. Flow Turbul Combust 2019. doi:10.1007/s10494-019-00013-3.

[36] Schuler P, Dullenkopf K, Bauer H-J. Investigation of the influence of different rim seal geometries in a low-Pressure turbine. Turbomach Parts A, B, and C 2011;7:715-29. doi:10.1115/GT2011-45682.

37] Tailliez C, Arntz A. CFD assessement of the use of exergy analysis for losses indentification in turbomachinery flows. In: 53rd 3AF international conference on applied aerodynamics, Salon de Provence, France; 2018.

[38] Tyacke JC, Tucker PG. Future use of large eddy simulation in aeroengines. J Turbomach 2015;137(August):GT2014-25434. doi:10.1115/1.4029363.

[39] Tyacke JC, Tucker PG, Jefferson-Loveday R, Vadlamani NR, Watson R, Naqavi I et al. Large eddy simulation for turbines: methodologies, cost and future outlooks. J Turbomach 2014. doi:10.1115/1.4025589.

[40] Wheeler APS, Sandberg R, Sandham ND, Pichler R, Michelassi V, Laskowski G. Direct numerical simulations of a high-Pressure turbine vane. J Turbomach 2016;138(7):71003. doi:10.1115/1.4032435.

[41] Wilcox DC. Formulation of the k- $\omega$ turbulence model revisited. AIAA J 2008. doi: $10.2514 / 1.36541$

[42] Zlatinov MB, Sooi Tan C, Montgomery M, Islam T, Harris M. Turbine hub and shroud sealing flow loss mechanisms. J Turbomach 2012;134(6):61027. doi:10. $1115 / 1.4006294$ 